Research Paper

\title{
Proteomics Analysis to Identify and Characterize the Biomarkers and Physical Activities of Non-Frail and Frail Older Adults
}

\author{
Ching-Hung Lin' ${ }^{1}$, Chen-Chung Liao ${ }^{2}$, Chi-Huang Huang 3 , Yu-Tang Tung 4 , Huan-Cheng Chang5, \\ Mei-Chich $\mathrm{Hsu}^{4,6,7 \bowtie}$, and Chi-Chang Huang ${ }^{\natural}$
}

1. Physical Education Office, Yuan Ze University, Taoyuan 32003, Taiwan;

2. Proteomics Research Center, National Yang-Ming University, Taipei 11221, Taiwan;

3. Department of Athletic Training and Health, National Taiwan Sport University, Taoyuan 33301, Taiwan;

4. Graduate Institute of Sports Science, National Taiwan Sport University, Taoyuan 33301, Taiwan;

5. Department of Family Medicine, Taiwan Landseed Hospital, Ping-Jen City, Taoyuan 32449, Taiwan;

6. Department of Sports Medicine, Kaohsiung Medical University, Kaohsiung 80708, Taiwan;

7. Kaohsiung Medical University Hospital, Kaohsiung Medical University, Kaohsiung 80708, Taiwan.

$\square$ Corresponding authors: Department of Sports Medicine, Kaohsiung Medical University, No. 100, Shih-Chuan 1st Road, Kaohsiung 80708, Taiwan (M.-C.H.); Graduate Institute of Sports Science, National Taiwan Sport University, No. 250, Wenhua 1st Rd., Guishan Township, Taoyuan County 33301, Taiwan (C.-C.H.). Tel.: +886-7-3121101 ext. 2646 (M.-C.H.); +886-3-328-3201 ext. 2619 (С.-C.H.). Electronic addresses: meichich@gmail.com (M.-C.H.); john5523@ntsu.edu.tw (C.-C.H.)

(c) Ivyspring International Publisher. This is an open access article distributed under the terms of the Creative Commons Attribution (CC BY-NC) license (https://creativecommons.org/licenses/by-nc/4.0/). See http://ivyspring.com/terms for full terms and conditions.

Received: 2016.09.18; Accepted: 2016.12.28; Published: 2017.02.23

\begin{abstract}
Globally, the proportion of older adults is increasing. Older people face chronic conditions such as sarcopenia and functional decline, which are often associated with disability and frailty. Proteomics assay of potential serum biomarkers of frailty in older adults. Older adults were divided into non-frail and frail groups ( $n=6$ each; 3 males in each group) in accordance with the Chinese-Canadian Study of Health and Aging Clinical Frailty Scale. Adults were measured for grip power and the 6-min walk test for physical activity, and venous blood was sampled after adults fasted for $8 \mathrm{~h}$. Ultra-high-performance liquid chromatography-tandem mass spectrometry was used for proteomics assay. The groups were compared for levels of biomarkers by $t$ test and Pearson correlation analysis. Non-frail and frail subjects had mean age $77.5 \pm 0.4$ and $77.7 \pm 1.6$ years, mean height $160.5 \pm 1.3$ and $156.6 \pm 2.9 \mathrm{~cm}$ and mean weight $62.5 \pm 1.2$ and $62.8 \pm 2.9 \mathrm{~kg}$, respectively. Physical activity level was lower for frail than non-frail subjects (grip power: $13.8 \pm 0.4$ vs $26.1 \pm 1.2$ $\mathrm{kg}$; 6-min walk test: $215.2 \pm 17.2$ vs $438.3 \pm 17.2 \mathrm{~m}$ ). Among 226 proteins detected, for 31 , serum levels were significantly higher for frail than non-frail subjects; serum levels of Ig kappa chain V-III region WOL, COX7A2, and albumin were lower. The serum levels of ANGT, KG and AT were 2.05-, 1.76- and 2.22-fold lower (all $p<0.05$; Figure 1A, $2 \mathrm{~A}$ and $3 \mathrm{~A}$ ) for non-frail than frail subjects and were highly correlated with grip power (Figure 1B, 2B and 3B). Our study found that ANGT, KG and AT levels are known to increase with aging, so degenerated vascular function might be associated with frailty. In total, 226 proteins were revealed proteomics assay; levels of angiotensinogen (ANGT), kininogen-1 (KG) and antithrombin III (AT) were higher in frail than non-frail subjects $(11.26 \pm 2.21$ vs $5.09 \pm 0.74 ; 18.42 \pm 1.36$ vs $11.64 \pm 1.36 ; 22.23 \pm 1.64$ vs $9.52 \pm 0.95$, respectively, $p<0.05)$. These 3 factors were highly correlated with grip power $(p<0.05)$, with higher correlations between grip power and serum levels of ANGT $(r=-0.89), K G(r=-0.90)$, and AT $(r=-0.84)$. In conclusion, this is the first study to demonstrate a serum proteomic profile characteristic of frailty in older adults. Serum ANGT, KG and AT levels could be potential biomarkers for monitoring the development and progression of frailty in older adults.
\end{abstract}

Key words: Strength, Proteomics, Angiotensinogen, Kininogen-1, Antithrombin III 


\section{Background}

Aging, affected by several factors, is often described as a syndrome of lack of resilience to stressors and decline in functional reserve of physiological systems. It affects human health and enhances exposure to diseases [1, 2]. Frailty is associated with impaired ability to endure and respond to stress. Fried et al. [1] operationalized frailty as weight loss, weak grip strength, self-reported exhaustion, slow walking speed and low physical activity. However, all of these characteristics are external indexes. $10.7 \%$ of older adults aged 65 to 74 years are frail [3]. Frail older adults have the higher risks of disabilities, fall incidents, hospitalization and death [4]. Frailty is negative associated with physical activity [5].

Blood serum, a complex body fluid, contains various proteins ranging in concentration over at least 9 orders of magnitude. One of the driving forces in proteomics is the discovery of biomarkers, proteins that change in concentration or state in associations with a specific biological process or disease [6]. Abnormal conditions such as allergy, infection or sedentary living usually accompany dysfunction or altered expression of certain proteins. Specific alterations among proteins can have physiologic meaning, so comparing these proteins is helpful in diagnoses because it provides valuable insight into the overall health state [7]. High-efficiency equipment and techniques are needed in analyzing the complicated protein composition in plasma [8]. Proteomics has been used to distinguish the diverse expression of specific proteins such as in degrees of schizophrenia [9], Parkinson's disease [10], and epithelial ovarian cancer from normal tissue [11].

We hypothesized that the proteome might be altered in frail older adults. We examined frailty in older adults and compared the proteome among frail and non-frail older adults.

\section{Methods}

\section{Subjects}

The institutional review board of Taiwan Landseed Hospital inspected all human experiments, and this study conformed to the guidelines of protocol IRB-11-24 approved by the institutional ethics committee. Subjects $\geq 65$ years old who could walk independently or rely on aids such as a cane and maintained their original lifestyle were selected. We excluded subjects with major diseases or terminal cancer, serious cardiovascular diseases, and central nervous system diseases. Subjects were divided by the Chinese-Canadian Study of Health and Aging Clinical Frailty Scale (CSHA-CFS) [12] into 2 groups $(n=6$ each; 3 males and 3 females each). All participants gave their signed consent to be in the study. Vigorous activities were forbidden for 3 days before the experiment, with maintenance of the original lifestyle.

\section{Study Design}

Measurement of physical activity was on alternate days and on two dates within a week. Venous blood was sampled and body composition data were collected after fasting for $8 \mathrm{~h}$. Measurement of physical activity was conducted at 9:00 am.

\section{Blood Collection}

Blood samples were collected by qualified nurses or medical examiners, with subjects fasting $8 \mathrm{hr}$ or more before collection. We collected $15 \mathrm{ml}$ blood from the cubital vein of left or right arm with vacutainers containing anticoagulant. Samples were centrifuged at $1500 \times g$ for $15 \mathrm{~min}$ and serum was separated and immediately stored at $-80^{\circ} \mathrm{C}$.

\section{Physical Activity Test}

Measurement of physical activity was testing for identification of the two items proposed by Fried et al. [1], hand-grip strength and walk speed. Grip strength was measured in kilograms by using a handheld dynamometer Grip-D (Talei, Japan). Width was adjusted for each subject before testing, then subjects stood with their elbow down. The best performances with maximum force lasting $2 \mathrm{sec}$ in both hands for 2 times were recorded and the average defined upper-body hand-grip strength, abbreviated as grip power.

To assess mobility, we referred to previous studies [13, 14] for cardiorespiratory endurance estimated by the 6-min walk test. Test was operated on adequate straight line or elliptic ground. Subjects were required to walk 6 minutes as fast as possible. Slowing down or resting midway was accepted. Distances were recorded and translated into walk speed.

\section{SDS-PAGE and In-Gel Digestion}

Protein samples ( $n=6$ each group; 3 males and 3 females each) extracted from blood serum were resolved by $10 \%$ SDS-PAGE. Briefly, $50 \mu \mathrm{g}$ of each protein sample was applied to gel in triplicate, and the sizes of proteins were visualized by staining with a staining kit after electrophoresis, then gels were destained by repeated washing in a solution of $25 \mathrm{mM}$ ammonium bicarbonate and 50\% (vol/vol) acetonitrile (1:1) until the protein bands were invisible. Gels were dried with use of a Speed-Vac (Thermo Electron, Waltham, Massachusetts, USA), 
then rehydrated with $2 \%$ (vol/vol) $\beta$-mercaptoethanol in $25 \mathrm{mM}$ ammonium bicarbonate and incubated at room temperature for $20 \mathrm{~min}$ in the dark. Cysteine alkylation was performed by adding an equal volume of $10 \%$ (vol/vol) 4-vinylpyridine in $25 \mathrm{mM}$ ammonium bicarbonate and 50\% (vol/vol) acetonitrile for $20 \mathrm{~min}$. The samples were washed by soaking in $1 \mathrm{ml}$ of $25 \mathrm{mM}$ ammonium bicarbonate for $10 \mathrm{~min}$. After Speed-Vac drying for $20 \mathrm{~min}$, in-gel trypsin digestion was carried out by incubating samples with 100 ng modified trypsin (Promega, Mannheim, Germany) in $25 \mathrm{mM}$ ammonium bicarbonate at $37^{\circ} \mathrm{C}$ overnight. The supernatant of the tryptic digest was transferred to an Eppendorf tube. Extraction of the remaining peptides was performed by adding $25 \mathrm{mM}$ ammonium bicarbonate in 50\% (vol/vol) acetonitrile, then the solution was incubated for $10 \mathrm{~min}$. The resulting digestions were dried in a Speed-Vac and stored at $-20^{\circ} \mathrm{C}$ until further analysis.

\section{Nanoflow Ultra-high-performance Liquid Chromatography-tandem Mass Spectrometry (nUPLC-MS/MS)}

Cryo-stored tryptic digestions were resuspended in $30 \mu \mathrm{l}$ of $0.1 \%$ (vol/vol) formic acid and analyzed by use of an online nanoAcquity ultra Performance LC (UPLC) system (Waters, Manchester, UK) coupled to a hybrid linear ion trap Orbitrap (LTQ-Orbitrap Discovery) mass spectrometer with a nanoelectrospray ionization source (Thermo Scientific, San Jose, CA). After loading the sample with a single injection model into the UPLC, peptides were captured and desalted on a C18 trapping cartridge (nanoAcquity UPLC Trap Column; Waters), then further separated on an analytical reverse-phase C18 tip column $(10 \mathrm{~cm} \times$ ID $75 \mu \mathrm{m}$ and $360 \mu \mathrm{m}$ in diameter; Poly Micro Technology). Mobile phase solvent A and B were prepared as $0.1 \%$ formic acid in water and in acetonitrile, respectively. The separation condition involved eluting the peptides from the column with a linear gradient of $3 \%$ to $40 \%$ B for 90 min, $40 \%$ to $95 \%$ B for $2 \mathrm{~min}$, and $95 \%$ B for $10 \mathrm{~min}$ at a flow rate of $0.5 \mu \mathrm{l} / \mathrm{min}$. The eluted peptides were ionized with spray voltage of $2.33 \mathrm{kV}$ and introduced into the mass spectrometer. Mass spectrometry data were obtained by a data-dependent acquisition method (isolation width: $2 \mathrm{Da}$ ), with one full MS survey scan (m/z: 200-1500) at a high resolution of 30000 full at width half-maximum followed by a MS/MS scan (m/z: 200-1500) of the six most intense multiply charged ions $(2+$ and $3+)$. Fragment ions of the each selected precursors were generated by collision-induced dissociation (CID) by using helium gas with collision energy of $35 \%$ (or $3.5 \mathrm{eV}$ ). The dynamic exclusion duration of precursors was set to
$120 \mathrm{~s}$ with an exclusion list size of 200.

\section{Mass Spectrometry}

LC-MS/MS raw data (.raw files) collected by Xcalibur 2.0.7 SR1 software (ThermoElectron, San Jose, CA) were converted into peak list files (.dta) by using our in-house software within a Microsoft VBA environment. The resulting .dta files were used to search against a UniProt rat protein database (containing 33,457 protein sequences; released on April, 2013; http://www.uniprot.org/) with an in-house TurboSequest search server (ver. 27, rev. 11; Thermo Electron, Waltham, MA). The following search parameters were incorporated: peptide mass tolerance, $3.5 \mathrm{Da}$; fragment ion tolerance, $1 \mathrm{Da}$; enzyme was set as trypsin; one missed cleavage allowed; peptide charge, $2^{+}$and $3^{+}$; and oxidation on methionine $(+16 \mathrm{Da})$ and vinylpyridine alkylation on cysteine $(+105.06 \mathrm{Da})$ allowed as variable modifications. TurboSequest results were filtered with criteria, and all accepted results had a delta $\mathrm{Cn}$ $($ DelCN $) \geq 0.1$. A protein was identified when at least two unique peptides matched, with the Xcorr score of each peptide $>2.5$. The false discovery rate (FDR, $\leq$ $1 \%)$ from the search against the decoy database was used to estimate the protein identifications. Label-free quantitative analysis with MS spectra counting involved an in-house tool within a Microsoft VBA environment. MS spectral counts were normalized to the total-identified spectra per biological sample and the proteins (containing at least 2 unique peptides) with a statistically significant higher or lower peptide counts in PM-NAFLD rats ( $t$ test; $p \leq 0.05$ ) were considered as differentially expressed. All LC-MS/MS .raw files in this study are accessible in the PeptideAtlas database (http://www.peptideatlas. org/) with the dataset identifier.

\section{Statistical Analysis}

Data are presented as means \pm SEM. An independent $t$ test was used for analyzing differences between groups. Correlation was analyzed by Pearson product-moment correlation. $p<0.05$ was considered statistically significant.

\section{Results and Comments}

This is the first study to demonstrate a serum proteomic profile characteristic of frailty in older adults. Serum ANGT, KG and AT levels could be potential biomarkers for monitoring the development and progression of frailty in older adults. Participant characteristics are shown in Table 1. Grip power, walk distance and speed were worse in frail than non-frail subjects $(13.8 \pm 1.07$ vs $26.1 \pm 3.02 \mathrm{~kg} ; 215.2 \pm 42.2$ vs $438.3 \pm 42.0 \mathrm{~m} ; \quad 35.9 \pm 7.0$ vs $73.1 \pm 7.0 \mathrm{~m} / \mathrm{min}$, 
respectively, $p<0.05)$. Our study found that grip power and 6-min-walk test have been shown to be predictive of frailty. Grip power and 6-min walk test have been found to be predictive of incident frailty. We found these characteristics to differ by frailty status, which is consistent with prior study including weak strength and slow walk speed among 5 indicators generalized as frailty [1]. Furthermore, decreased strength and endurance compared to the same age were found objective indicators of frailty. We found $46 \%$ and $51 \%$ reduced strength and 6-min walk distance, respectively, in our subjects. Hand grip test has been found highly associated with whole-body muscle strength, although measured easily by power from arms [15, 16]. Also, the performance of hand grip by older adults is strongly related to mortality and disability in older adults [15-17]. Therefore, the strength is to some degree representative of individual frailty. The 6-min walk test, focusing on lower body activity, was found predictive of frailty by observing worsening cardiorespiratory endurance and walk speed.

Table 1. Characteristics of non-frailty and frailty subjects.

\begin{tabular}{lll}
\hline Variable & Non-Frailty & Frailty \\
\hline Basic demographics & & \\
Sex (men/women, n) & $(3 / 3)$ & $(3 / 3)$ \\
Age (yr) & $77.5 \pm 0.4$ & $77.7 \pm 1.6$ \\
Height (cm) & $160.5 \pm 1.3$ & $156.6 \pm 2.9$ \\
Body weight (kg) & $62.5 \pm 1.2$ & $62.8 \pm 2.9$ \\
Heart rate (beats/min) & $77.2 \pm 4.9$ & $77.5 \pm 1.7$ \\
SBP (mmHg) & $147.3 \pm 8.8$ & $135.3 \pm 9.9$ \\
DBP (mmHg) & $85.2 \pm 11.0$ & $80.7 \pm 12.0$ \\
Functional status & & \\
Right hand grip strength $(\mathrm{kg})$ & $27.3 \pm 1.3$ & $14.3 \pm 0.6^{*}$ \\
Left hand grip strength $(\mathrm{kg})$ & $25.0 \pm 1.2$ & $13.4 \pm 0.4^{*}$ \\
Grip power (kg) & $26.1 \pm 1.2$ & $13.8 \pm 0.4^{*}$ \\
6-min-walk distance $(\mathrm{m})$ & $438.3 \pm 17.2$ & $215.2 \pm 17.2^{*}$ \\
6-min-walk speed (m/min) & $73.1 \pm 2.9$ & $35.9 \pm 2.9^{*}$ \\
\hline
\end{tabular}

Data are mean \pm SEM for $n=6$ subjects per group. Data in the same row with superscript symbol "* " differ significantly, $p<0.05$ by $t$-test. SBP, systolic blood pressure; DBP, diastolic blood pressure.

Among 226 proteins detected, for 31, serum levels (P00450, Q5T985, P08603, Q9UP60, P02790, P01009, Q9P173, P10643, D3DNU8, P04004, P02763, B4E1Z4, Q6MZV7, C9JV77, B4E1C2, Q86U78, P13671, P04003, G3V5I3, P01008, P01598, P10909, P00738, P01031, Q68CX6, P01777, Q68CK4 and Q6MZV6) were significantly higher for frail than non-frail subjects; serum levels of Ig kappa chain V-III region WOL (P01623), COX7A2 (Q496I0), and albumin (P02768) were lower (Table 2). The serum levels of ANGT, KG and AT were 2.05-, 1.76- and 2.22-fold lower (all $p<0.05$; Figure 1A, 2A and 3A) for non-frail than frail subjects. In addition, serum ANG level was negatively correlated with grip power $(r=-0.89, p<$
0.05) in non-frail elders (Figure 1B), and serum KG and AT levels were negatively correlated with grip power $(r=-0.90, p<0.05$ and $r=-0.84, p<0.05$, respectively) in elders with frailty (Figures $2 \mathrm{~B}$ and $3 \mathrm{~B}$ ).

(A)

(B)
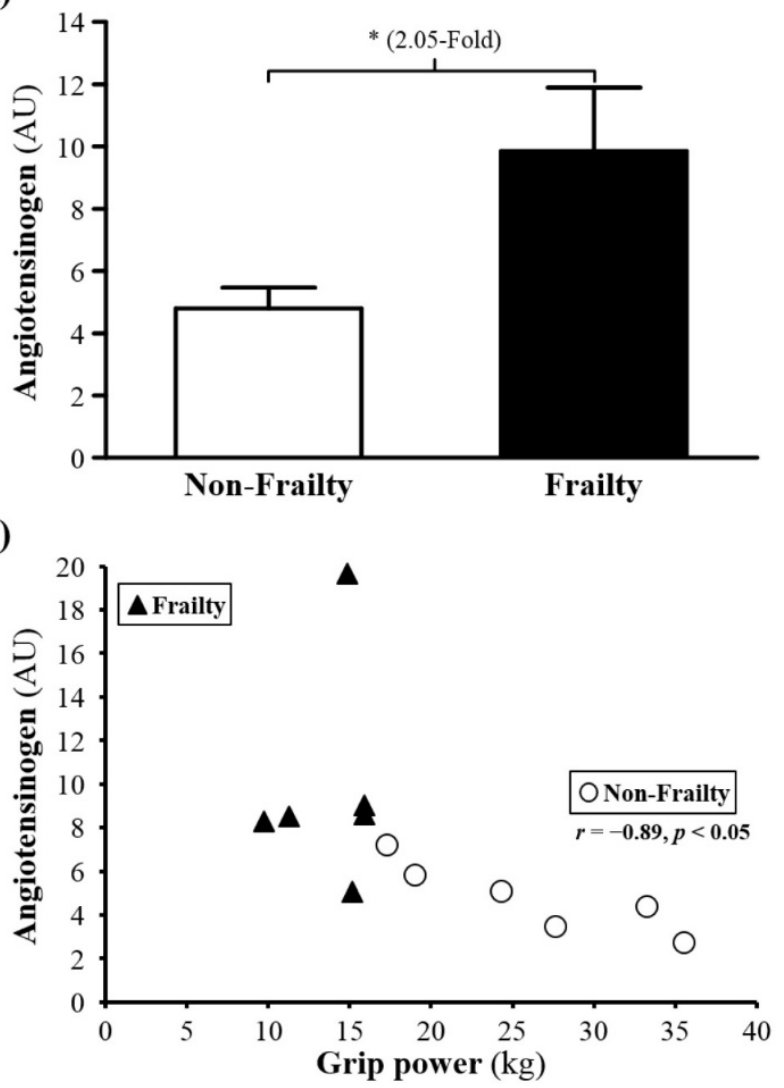

Figure. 1 (A) Serum levels of angiotesinogen (ANG) in frailty and non-frailty. *, $p<0.05$. (B) Relationship between the grip power and serum ANG level. Serum ANG level was negatively correlated with grip power $(r=-0.89, p<0.05)$ in elders with non-frailty. Elders with frailty and non-frailty are represented by the filled triangles and open circles, respectively.

Our study found that ANGT, KG and AT levels are known to increase with aging, so degenerated vascular function might be associated with frailty. Elevated level of ANGT and KG might result in decreased strength. ANGT, regulating blood pressure, body fluid and homeostasis of sodium and potassium, is the first-stage reactive substance in the renin-angiotensin system (RAS). ANGT, secreted by the liver, is transformed by renin secreted by the kidney to be angiotensin I and then angiotensin II by angiotensin-converting enzyme. RAS affects the increase in blood pressure, particularly by vasoconstriction. In addition, RAS may also have negative effects, including causing thrombosis or inhibiting angiogenesis. Although ANGT does not directly affect blood pressure, it is the source of the RAS mechanism. Thus, much literature has examined the relationship between RAS and blood pressure. 
Changes in blood pressure in some patients were found associated with high ANGT level [18], and high concentration of ANGT was found in some families with a history of hypertension [19]. A positive association of ANGT and blood pressure was determined [20] as well as increased systolic blood pressure observed with increased ANGT, age or even obesity [21, 22]. Furthermore, animal models with transgenic or knockout genes also demonstrated that increased ANGT was associated with increased blood pressure [23, 24].

Frailty, is usually accompanied by elevated blood pressure, which may be higher whether exceeding the normal range or not [25-27]. Yoshida et al. [27] found that older adults $\geq 70$ years old with 2 years of frailty showed significantly increased blood pressure and decreased grip power. We found that frail adults also had significantly reduced grip power but no reduced absent in the blood pressure compared to the same age. As shown in the Figure 2, it might be inevitable of increasing blood pressure in the frailty since ANGT in frailty group was significantly higher than the other groups. High ANGT concentration might be observed prior to elevated blood pressure in the frailty.

Table 2. Differentially expressed proteins in non-frailty and frailty samples

\begin{tabular}{|c|c|c|c|c|c|}
\hline Protein-ID & Protein Name & Non-Frailty & Frailty & $p$ value & Fold \\
\hline P01623 & Ig kappa chain V-III region WOL & $4.68 \pm 0.51$ & $1.28 \pm 0.92$ & 0.0089 & -3.65 \\
\hline Q49610 & COX7A2 protein & $13.15 \pm 1.97$ & $6.23 \pm 1.47$ & 0.0184 & -2.11 \\
\hline P02768 & Serum albumin & $1466.80 \pm 25.91$ & $1247.41 \pm 23.88$ & 0.0001 & -1.18 \\
\hline P00450 & Ceruloplasmin & $97.02 \pm 1.59$ & $116.98 \pm 4.73$ & 0.0025 & 1.21 \\
\hline Q5T985 & Inter-alpha-trypsin inhibitor heavy chain $\mathrm{H} 2$ & $54.63 \pm 3.76$ & $69.59 \pm 2.65$ & 0.0086 & 1.27 \\
\hline P08603 & Complement factor $\mathrm{H}$ & $71.63 \pm 2.55$ & $94.21 \pm 3.99$ & 0.0008 & 1.32 \\
\hline Q9UP60 & SNC73 protein & $79.39 \pm 7.37$ & $105.07 \pm 3.13$ & 0.0094 & 1.32 \\
\hline P02790 & Hemopexin & $31.81 \pm 1.80$ & $42.12 \pm 3.25$ & 0.0197 & 1.32 \\
\hline P01009 & Alpha-1-antitrypsin & $66.29 \pm 6.92$ & $97.8 \pm 8.74$ & 0.0180 & 1.48 \\
\hline Q9P173 & PRO2275 & $27.50 \pm 2.00$ & $40.91 \pm 3.41$ & 0.0069 & 1.49 \\
\hline P10643 & Complement component C7 & $8.22 \pm 0.98$ & $12.36 \pm 0.86$ & 0.0098 & 1.50 \\
\hline D3DNU8 & Kininogen 1, isoform CRA_a & $11.64 \pm 1.36$ & $18.42 \pm 1.36$ & 0.0055 & 1.58 \\
\hline P04004 & Vitronectin & $10.67 \pm 0.77$ & $17.21 \pm 1.61$ & 0.0043 & 1.61 \\
\hline P02763 & Alpha-1-acid glycoprotein 1 & $5.20 \pm 1.24$ & $9.36 \pm 0.48$ & 0.0109 & 1.8 \\
\hline B4E1Z4 & Complement factor B & $21.69 \pm 5.52$ & $41.87 \pm 3.8$ & 0.0131 & 1.93 \\
\hline Q6MZV7 & Putative uncharacterized protein & $52.13 \pm 8.60$ & $100.89 \pm 11.98$ & 0.0080 & 1.94 \\
\hline C9JV77 & Alpha-2-HS-glycoprotein & $3.58 \pm 0.82$ & $7.62 \pm 0.79$ & 0.0054 & 2.13 \\
\hline B4E1C2 & Kininogen 1 , isoform CRA_b & $6.19 \pm 1.98$ & $13.30 \pm 1.37$ & 0.0146 & 2.15 \\
\hline Q86U78 & Angiotensinogen (Serine (Or cysteine) proteinase inhibitor, clade A & $5.09 \pm 0.74$ & $11.26 \pm 2.21$ & 0.0246 & 2.21 \\
\hline P13671 & Complement component C6 & $6.44 \pm 1.10$ & $14.36 \pm 0.70$ & 0.0001 & 2.23 \\
\hline P04003 & C4b-binding protein alpha chain & $5.88 \pm 1.18$ & $13.15 \pm 1.97$ & 0.0101 & 2.24 \\
\hline G3V5I3 & Alpha-1-antichymotrypsin & $11.18 \pm 2.23$ & $25.32 \pm 3.10$ & 0.0041 & 2.27 \\
\hline P01008 & Antithrombin III & $9.52 \pm 0.95$ & $22.23 \pm 1.64$ & 0.0000 & 2.33 \\
\hline P01598 & Ig kappa chain V-I region EU & $0.95 \pm 0.43$ & $2.29 \pm 0.41$ & 0.0469 & 2.41 \\
\hline P10909 & Clusterin & $3.94 \pm 1.21$ & $10.04 \pm 2.07$ & 0.0294 & 2.55 \\
\hline P00738 & Haptoglobin & $9.03 \pm 4.16$ & $27.16 \pm 3.27$ & 0.0065 & 3.01 \\
\hline P01031 & Complement C5 & $3.48 \pm 1.04$ & $11.21 \pm 2.55$ & 0.0185 & 3.22 \\
\hline Q68CX6 & Putative uncharacterized protein DKFZp686O13149 & $16.56 \pm 10.50$ & $55.57 \pm 6.67$ & 0.0106 & 3.35 \\
\hline P01777 & Ig heavy chain V-III region TEI & $3.68 \pm 1.00$ & $12.92 \pm 1.68$ & 0.0008 & 3.51 \\
\hline Q68CK4 & Leucine-rich alpha-2-glycoprotein & $0.98 \pm 0.64$ & $3.64 \pm 0.90$ & 0.0375 & 3.72 \\
\hline Q6MZV6 & Putative uncharacterized protein DKFZp686L19235 & $3.12 \pm 3.12$ & $17.23 \pm 5.50$ & 0.0498 & 5.52 \\
\hline O75882 & Attractin & $0.57 \pm 0.57$ & $3.38 \pm 0.33$ & 0.0016 & 5.97 \\
\hline P09871 & Complement $\mathrm{C} 1 \mathrm{~s}$ subcomponent & $0.78 \pm 0.78$ & $4.68 \pm 0.79$ & 0.0054 & 6.02 \\
\hline P02748 & Complement component C9 & $0.75 \pm 0.49$ & $4.88 \pm 0.58$ & 0.0003 & 6.55 \\
\hline P19652 & Alpha-1-acid glycoprotein 2 & N.D. ${ }^{a}$ & $2.04 \pm 0.72$ & 0.0179 & + \\
\hline Q9H382 & Fibronectin 1 & N.D. & $2.72 \pm 1.12$ & 0.0357 & + \\
\hline F8W7M9 & Fibulin-1 & N.D. & $1.98 \pm 0.78$ & 0.0291 & + \\
\hline P01596 & Ig kappa chain V-I region CAR & N.D. & $1.21 \pm 0.40$ & 0.0121 & + \\
\hline P01620 & Ig kappa chain V-III region SIE & N.D. & $3.93 \pm 1.01$ & 0.0031 & + \\
\hline P04208 & Ig lambda chain V-I region WAH & N.D. & $0.84 \pm 0.38$ & 0.0494 & + \\
\hline Q6GMX6 & IGH@ protein & N.D. & $59.01 \pm 8.84$ & 0.0001 & + \\
\hline Q9NVE5 & Ubiquitin carboxyl-terminal hydrolase 40 & N.D. & $1.49 \pm 0.47$ & 0.0102 & + \\
\hline D3DVD8 & Spectrin, alpha, erythrocytic 1 (Elliptocytosis 2), isoform CRA_c & $3.56 \pm 1.07$ & N.D. & 0.0077 & - \\
\hline
\end{tabular}


(A)

(B)
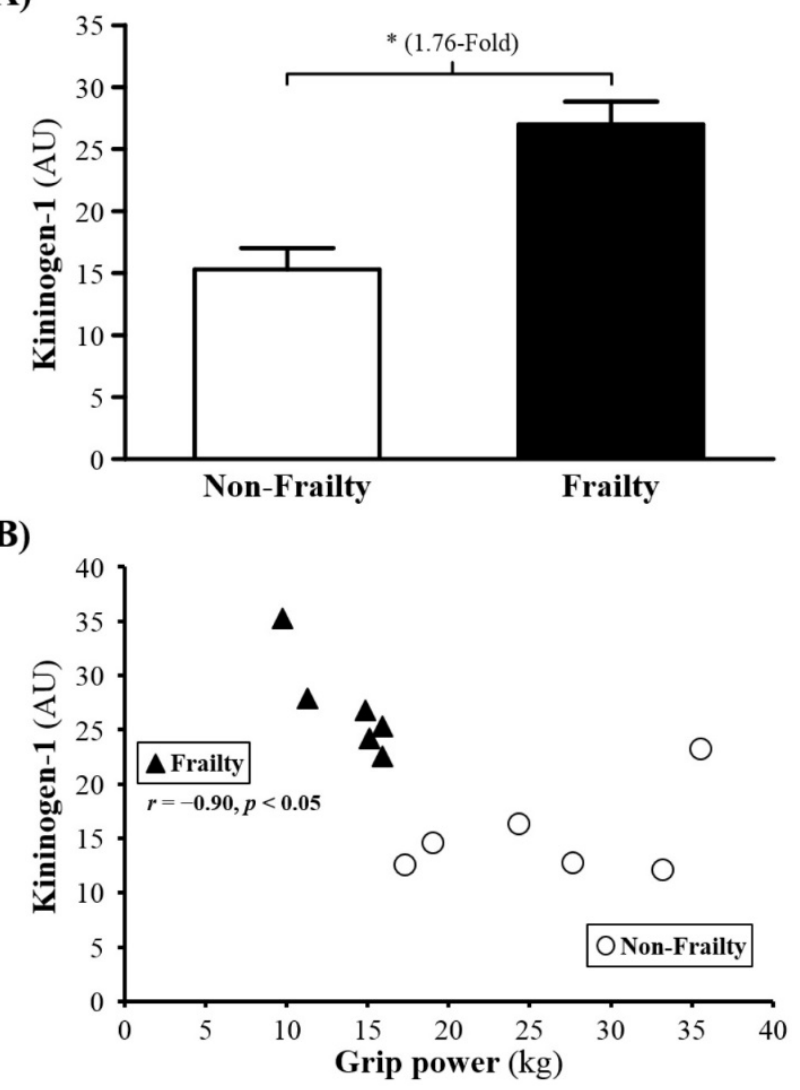

Figure. 2 (A) Serum levels of kininogen-1 (KG) in frailty and non-frailty. *, $p<$ 0.05. (B) Relationship between grip power and serum KG level. Serum KG level was negatively correlated with grip power $(r=-0.90, p<0.05)$ in elders with frailty. Elders with frailty and non-frailty are represented by the filled triangles and open circles, respectively.

KG is one of the initial reaction substances in kallikrein-kinin system (KKS). KG will be transformed into kallikrein and thereby changed into kallidin stored in tussue and bradykinin in plasma from low molecular weight kininogen (LMWK) and high molecular weight kininogen, (HMWK) respectively. Researchers have indicated that KG and KKS has been associated with pulmonary vascular injury, vascular (remodeling) and inflammation, suggesting that KG has anti-inflammatory effects [28]. Other research also pointed out that significantly reduced KG was observed in damaged liver function or cirrhosis patient [29]. Promoted (intravascular coagulation) was caused during the process of cirrhosis and reduced KG [30], but more studies have found the negative effect on blood pressure because of KG reduction [31, 32], since KKS and KG are found to improving (vosodilation) including skeletal muscle [33].

Our findings are also supportive of the observation from previous reports that raised blood pressure due to insulin resistance or impaired insulin tolerance was improved by increased KG and KKS which assuredly enhanced (angiogenesis) [34-37].
Since KG can be traced from KKS, it is undeniable that some fundamental implications to the body with increased KG although documents above focused on (angiogenesis) and (vosodilation) effects of KG and KKS. Referring to the connection between KG, age or diseases, $K G$ in frailty group was significantly higher than the other groups. Studies have indicated that KG increased with age $[38,39]$, and which may attached with physiological disorders of vascular function caused by age [40].

(A)

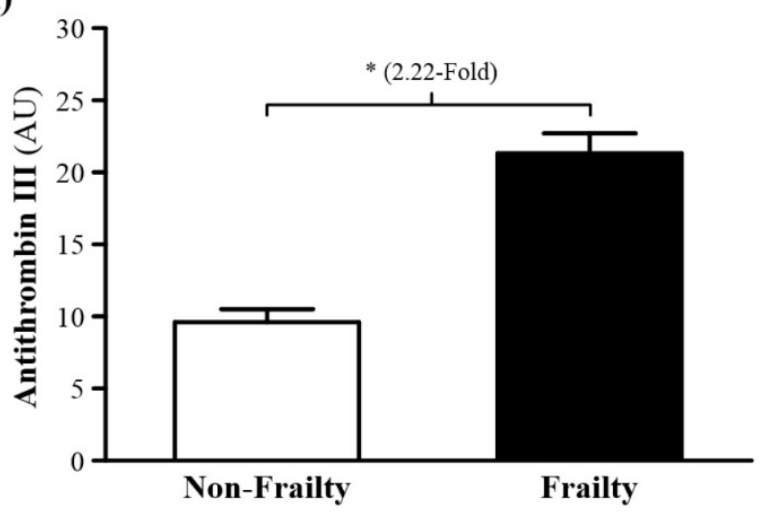

(B)

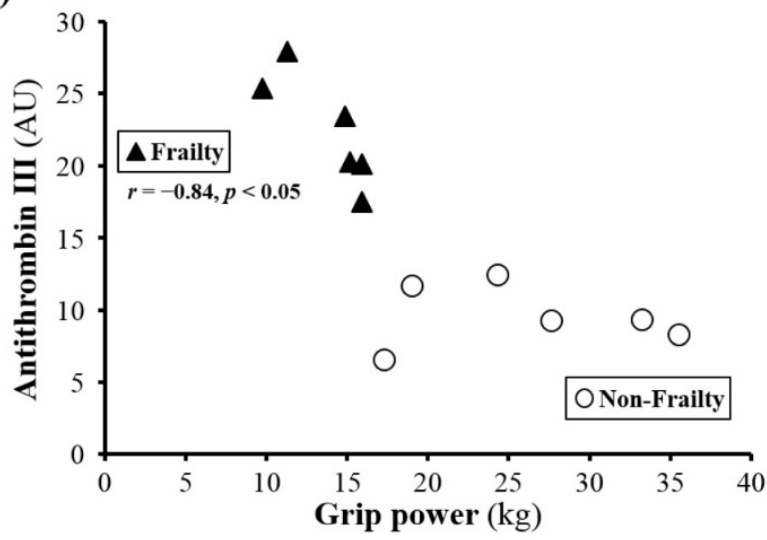

Figure. 3 (A) Serum levels of antithrombin III (AT) in frailty and non-frailty. * $p<0.05$. (B) Relationship between grip power and serum AT level. Serum AT level was negatively correlated with grip power $(r=-0.84, p<0.05)$ in elders with frailty. Elders with frailty and non-frailty are represented by the filled triangles and open circles, respectively.

Focusing on diseases, documents observed higher blood pressure with decreased KG [41, 42]. However, later study indicated that higher blood pressure also reflected higher KG [43]. Besides, there are studies also indicate incused KG was an important characterization of early gastric cancer stages [44] as well as aging and inflammation in animal studies which pointed out increased KG with frailty nor inflammation[45, 46]. Increasing KG was found by other research lasting even 2.8-4 months in dying animals [47]. Briefly reviewing, we demonstrated the counterbalance of mechanism between RAS and KKS. Indeed, in fact, both are recognized responsible for 
vascular regulation, including contraction, relaxation, inflammation and alterations in blood pressure [48]. Under certain circumstances, KKS is considered to be negative feedback after RSA overexpression in order to maintain homeostasis [49]. The study found that increasing level of ANGT and KG significantly is consistent to the counterbalance of its mechanism, which may also explain why blood pressure-increased ANGT in frailty was significantly higher than other group but absent in real high blood pressure.

There is significant negative correlation between KG and strength in frailty group but without other group. There are few reports discussing directly the association of KG and strength, but vascular physiologically dysfunction was found in individuals lacking of KG [40]. Further, some scholars have found less KG significantly in muscle atrophy [50]. It seems that in order to balance the internal negative effects including increased blood pressure brought by ANGT or inhibition against angiogenesis although KG was demonstrated to cause a positive regulation. Therefore, high KG level in frailty fully indicated certain decline in physiological reserve capacity, which is in accordance with the performance of muscle strength.

Antithrombin III (AT), an inhibitor of (serine protease), might play a key role in elderly aging process. It protects our body from forming thrombus by inhibiting thrombin, AT, thromboplastin IXa, Xa, Xia, XIIa, plasmin and kallikreihn. It serves as 70-90\% anticoagulant and can be activated 100 times by heparin. In general, AT decreased gradually with age [51]. Although some studies have shown higher AT in the elderly than young, like this study in which [52] found induced AT in healthy aging female compare to aged male and younger female rats. Reduced AT protein is considered a decline in functional capacity [53], whereas the increase in the AT is associated with primary defense mechanism [54] or anti-inflammation [55], especially for the inhibition of (coagulation factor). For this reason, (thrombin-antithrombin III complex) was found increased compared to the younger [56]. That study also found patients with normal ECG but peripheral arterial disease have a higher AT content compared with the same disease and abnormal ECG patients. Another study also found an increase in AT will elevate the risk of cardiovascular disease, but low AT in severe cardiovascular disease [57]. Previous study revealed that reduced AT, as well as age and hypertention, was lighly associated with coronary disease while investigating the relation of coronary disease and biochemical factors [58]. This study illustrated that in order to cope with disease during initial period, nagative feedback will promote AT in the frailty since nagative effects were caused by degeneration of body.

The study found that muscle strength showed a negative correlation with AT in frailty group but not in non-frailty group. Increased AT may be a reflection of body functional decline. It is widely accepted that physical activity drops down as aging, while protective measures well be adopted to prevent it. We observed that decreased physical activity followed by increased AT resulted from negative feedback with aging. Previous studies have shown that AT supplementation can reduce muscle damage AT [55], strengthen the blood capillary and increase skeletal muscle blood flow [59]. Those literatures present the muscle-protective effect of AT and indirectly prevent the loss of muscle strength although physical activity in these studies are not directly known to maintain or increase. Increased AT did not assist physical activity to meet to normal adults in frailty group. However, if there was not negative-feedback increase in AT, frailty status would become even more severe. Instead of a mortal or deadly disease, frailty might be a reflection to the degree of body degeneration through regulation of AT. Thus, frailty symptoms or early-stage phenotype might be improved with adequate repair.

Lower physical activity was actually observed in questionnaire-selected frailty subjects. By demonstrating the serum proteomic profiles characteristic of frailty, we found the interaction between degeneration of vascular function and resulted complementary as ANGT and KG are known the increase with aging states. In addition to the decline in strength, increasing serum AT level with ageing might be the fundamental proteomic biomarkers to the frailty.

\section{Conclusions}

The present study found negative and high correlations between the function of grip strength and serum ANGT, KG and AT levels. This association suggests that serum ANGT, KG and AT levels could serve as potential biomarkers for monitoring the development and progression of frailty for elder people.

\section{Authors' contributions:}

Ching-Hung Lin, Chi-Huang Huang, Mei-Chich $\mathrm{Hsu}$, and Chi-Chang Huang conceived of the study and supervised the study design. Ching-Hung Lin and Chen-Chung Liao carried out the laboratory experiments, analyzed the data, interpreted the results and wrote the manuscript. Ching-Hung Lin, Chi-Huang Huang, Huan-Cheng Chang and Chi-Chang Huang planned the project and recruited 
subjects. Chen-Chung Liao, Mei-Chich Hsu and Chi-Chang Huang contributed reagents, materials, analysis tools. Ching-Hung Lin, Yu-Tang Tung and Chi-Chang Huang prepared figures, edited and revised manuscript. All authors discussed the results and implications on the manuscript at all stages. All authors read and approved the final manuscript.

\section{Acknowledgements}

The corresponding author acknowledges the Ministry of Science and Technology (MOST) of Taiwan, the successor to the National Science Council (grants no. grant no. NSC-100-2410-H179-012 and MOST-104-2410-H-037-004-MY2), for financial support. We also thank Dr, Kuei-Yu Chien for many constructive suggestions during the experiment.

\section{Competing Interests}

The authors have declared that no competing interest exists.

\section{References}

1. Fried LP, Tangen CM, Walston J, Newman AB, Hirsch C, Gottdiener J, Seeman T, Tracy R, Kop WJ, Burke G, McBurnie MA. Frailty in older adults: evidence for a phenotype. J Gerontol A Biol Sci Med Sci. 2001;56:M146-56.

2. Lodovico B, Martine E. Biological Basis Of Geriatric Oncology. UAS: Springer Science + Business Media, Inc. 2005

3. Collard RM, Boter H, Schoevers RA, Oude Voshaar RC. Prevalence of frailty in community-dwelling older persons: A systematic review. J Am Geriatr Soc. 2012; 60:1487-1492.

4. Clegg A, Young J, Iliffe S, Olde Rikkert M, Rockwood K. Frailty in elderly people. Lancet. 2013; 381:752-762.

5. Fried LP, Tangen CM, Walston J, Newman AB, Hirsch C, Gottdiener J, Seeman T, Tracy R, Kop WJ, Burke G, McBurnie MA, Cardiovascular Health Study Collaborative Research Group. Frailty in older adults. evidence for a phenotype. J Gerontol A Biol Sci Med Sci. 2001; 56:m146-m157.

6. Adkins JN, Varnum SM, Auberry KJ, Moore RJ, Angell NH, Smith RD, Springer DL, Pounds JG. Toward a human blood serum proteome: analysis by multidimensional separation coupled with mass spectrometry. Mol Cell Proteomics. 2002; 1:947-955

7. Ilyin SE, Belkowski SM, Plata-Salaman CR. Biomarker discovery and validation: technologies and integrative approaches. Trends Biotechnol. 2004;22:411-6.

8. Quadroni M, James P. Proteomics and automation. Electrophoresis. 1999;20:664-77.

9. Levin Y, Schwarz E, Wang L, Leweke FM, Bahn S. Label-free LC-MS/MS quantitative proteomics for large-scale biomarker discovery in complex samples. J Sep Sci. 2007, 30:2198-2203.

10. Xun Z, Kaufman TC, Clemmer DE. Stable isotope labeling and label-free proteomics of Drosophila parkin null mutants. J Proteome Res. 2009;8:4500-10.

11. Lorkova L, Pospisilova J, Lacheta J, Leahomschi S, Zivny J, Cibula D, Petrak J. Decreased concentrations of retinol-binding protein 4 in sera of epithelial ovarian cancer patients: a potential biomarker identified by proteomics. Oncol Rep. 2012;27:318-24.

12. Chan DC, Tsou HH, Chen CY. Validation of the Chinese-Canadian study of health and aging clinical frailty scale (CSHA-CFS) telephone version. Arch Gerontol Geriatr. 2010;50:e74-80.

13. Curb JD, Ceria-Ulep CD, Rodriguez BL, Grove J, Guralnik J, Willcox BJ, Donlon TA, Masaki KH, Chen R. Performance-based measures of physical function for high-function populations. J Am Geriatr Soc. 2006;54:737-42.

14. Wang MY, Flanagan SP, Song JE, Greendale GA, Salem GJ. Relationships among body weight, joint moments generated during functional activities, and hip bone mass in older adults. Clin Biomech (Bristol, Avon). 2006;21:717-25.

15. Bohannon RW. Hand-grip dynamometry predicts future outcomes in aging adults. J Geriatr Phys Ther. 2008·31:3-10.

16. Bohannon RW. Is it legitimate to characterize muscle strength using a limited number of measures? J Strength Cond Res. 2008;22:166-73.

17. Sasaki H, Kasagi F, Yamada M, Fujita S. Grip strength predicts cause-specific mortality in middle-aged and elderly persons. Am J Med. 2007;120:337-42.

18. Walker WG, Whelton PK, Saito H, Russell RP, Hermann J. Relation between blood pressure and renin, renin substrate, angiotensin II, aldosterone and urinary sodium and potassium in 574 ambulatory subjects. Hypertension. 1979;1:287-91

19. Watt GC, Harrap SB, Foy CJ, Holton DW, Edwards HV, Davidson HR, Connor $\mathrm{JM}$, Lever AF, Fraser R. Abnormalities of glucocorticoid metabolism and the renin-angiotensin system: a four-corners approach to the identification of genetic determinants of blood pressure. J Hypertens. 1992;10:473-82.

20. Robinson M, Williams SM. Role of two angiotensinogen polymorphisms in blood pressure variation. J Hum Hypertens. 2004;18:865-9.

21. Srikanthan K, Feyh A, Visweshwar H, Shapiro JI, Sodhi K. Systematic Review of Metabolic Syndrome Biomarkers: A Panel for Early Detection, Management, and Risk Stratification in the West Virginian Population. Int J Med Sci. 2016;13:25-38

22. Rankinen T, Gagnon J, Pérusse L, Rice T, Leon AS, Skinner JS, Wilmore JH, Rao DC, Bouchard C. Body fat, resting and exercise blood pressure and the angiotensinogen M235T polymorphism: the heritage family study. Obes Res. 1999;7:423-30

23. Kim HS, Krege JH, Kluckman KD, Hagaman JR, Hodgin JB, Best CF, Jennette JC, Coffman TM, Maeda N, Smithies O. Genetic control of blood pressure and the angiotensinogen locus. Proc Natl Acad Sci U S A. 1995;92:2735-9.

24. Kimura S, Mullins JJ, Bunnemann B, Metzger R, Hilgenfeldt U, Zimmermann F, Jacob H, Fuxe K, Ganten D, Kaling M. High blood pressure in transgenic mice carrying the rat angiotensinogen gene. EMBO J. 1992;11:821-7.

25. Fattori A, Santimaria MR, Alves RM, Guariento ME, Neri AL. Influence of blood pressure profile on frailty phenotype in community-dwelling elders in Brazil - FIBRA study. Arch Gerontol Geriatr. 2013;56:343-9.

26. Jeffery CA, Shum DW, Hubbard RE. Emerging drug therapies for frailty. Maturitas. 2013;74:21-5.

27. Yoshida H, Nishi M, Watanabe N, Fujiwara Y, Fukaya T, Ogawa K, Kim MJ, Lee S, Shinkai S. Predictors of frailty development in a general population of older adults in Japan using the Frailty Index for Japanese elderly patients. Nihon Ronen Igakkai Zasshi. 2012;49:442-8.

28. Chao J, Simson JA, Chung P, Chen LM, Chao L. Regulation of kininogen gene expression and localization in the lung after monocrotaline-induced pulmonary hypertension in rats. Proc Soc Exp Biol Med. 1993;203:243-50.

29. Cugno M, Scott CF, Salerno F, Lorenzano E, Muller-Esterl W, Agostoni A, Colman RW. Parallel reduction of plasma levels of high and low molecular weight kininogen in patients with cirrhosis. Thromb Haemost. 1999;82:1428-32.

30. Saito H, Goldsmith G, Waldmann R. Fitzgerald factor (high molecular weight kininogen) clotting activity in human plasma in health and disease in various animal plasmas. Blood. 1976;48:941-7.

31. Almeida FA, Stella RC, Voos A, Ajzen H, Ribeiro AB. Malignant hypertension: a syndrome associated with low plasma kininogen and kinin potentiating factor. Hypertension. 1981;3:II-46-9.

32. Mohamed M, Larmie ET, Singh HJ, Othman MS. Tissue kallikrein and kininogen levels in fetoplacental tissues from normotensive pregnant women and women with pregnancy-induced hypertension. Eur J Obstet Gynecol Reprod Biol. 2007;134:15-9.

33. Takano M, Sakanaka F, Yayama K, Okamoto H. Tissue-Specific expression of rat kininogen mRNAs. Biol Pharm Bull. 2000;23:1239-1242.

34. Wicklmayr M, Brunnbauer $\mathrm{H}$, Dietze $\mathrm{G}$. The kallikrein-kinin-prostaglandin system: involvement in the control of capillary blood flow and substrate metabolism in skeletal muscle tissue. Adv Exp Med Biol. 1983;156:625-38.

35. Wicklmayr M, Rett K, Baldermann H, Dietze G. The kallikrein/kinin system in the pathogenesis of hypertension in diabetes mellitus. Diabete Metab. 1989;15:306-10.

36. Colman RW, Pixley RA, Sainz IM, Song JS, Isordia-Salas I, Muhamed SN, Powell JA Jr, Mousa SA. Inhibition of angiogenesis by antibody blocking the action of proangiogenic high-molecular-weight kininogen. J Thromb Haemost. 2003;1:164-70.

37. Emanueli C, Minasi A, Zacheo A, Chao J, Chao L, Salis MB, Straino S, Tozzi MG, Smith R, Gaspa L, Bianchini G, Stillo F, Capogrossi MC, Madeddu P. Local delivery of human tissue kallikrein gene accelerates spontaneous angiogenesis in mouse model of hindlimb ischemia. Circulation. 2001;103:125-32.

38. Acuna-Castillo C, Leiva-Salcedo E, Gomez CR, Perez V, Li M, Torres C, Walter R, Murasko DM, Sierra F. T-kininogen: a biomarker of aging in Fisher 344 rats with possible implications for the immune response. J Gerontol A Biol Sci Med Sci. 2006;61:641-9.

39. Kleniewski J, Czokalo M. Plasma kininogen concentration: the low level in cord blood plasma and age dependence in adults. Eur J Haematol. 1991; 46:257-62.

40. Perez V, Leiva-Salcedo E, Acuna-Castillo C, Aravena M, Gomez C, Sabaj V, Colombo A, Nishimura S, Pérez C, Walter R, Sierra F. T-kininogen induces endothelial cell proliferation. Mech Ageing Dev. 2006;127:282-9.

41. Majima M, Mizogami S, Kuribayashi Y, Katori M, Oh-ishi S. Hypertension induced by a nonpressor dose of angiotensin II in kininogen-deficient rats. Hypertension. 1994;24:111-9.

42. Majima M, Yoshida O, Mihara H, Muto T, Mizogami S, Kuribayashi $Y$, Katori $\mathrm{M}$, Oh-ishi S. High sensitivity to salt in kininogen-deficient brown Norway Katholiek rats. Hypertension. 1993;22:705-14.

43. Zhao W, Wang Y, Wang L, Lu X, Yang W, Huang J, Chen S, Gu D. Gender-specific association between the kininogen 1 gene variants and essential hypertension in Chinese Han population. J Hypertens. 2009;27:484-90. 
44. Umemura H, Togawa A, Sogawa K, Satoh M, Mogushi K, Nishimura M, Matsushita K, Tanaka H, Takizawa H, Kodera Y, Nomura F. Identification of a high molecular weight kininogen fragment as a marker for early gastric cancer by serum proteome analysis. J Gastroenterol. 2011;46:577-85.

45. Sierra F, Fey GH, Guigoz Y. T-kininogen gene expression is induced during aging. Mol Cell Biol. 1989;9:5610-6.

46. Walter R, Murasko DM, Sierra F. T-kininogen is a biomarker of senescence in rats. Mech Ageing Dev. 1998;106:129-144.

47. Sierra F, Coeytaux S, Juillerat M, Ruffieux C, Gauldie J, Guigoz Y. Serum T-kininogen levels increase two to four months before death. J Biol Chem. 1992;267:10665-9.

48. Brasier AR, Recinos A3 ${ }^{\text {rd }}$, Eledrisi M.S. Vascular inflammation and the renin-angiotensin system. Arterioscler Thromb Vasc Biol. 2002;22:1257-66.

49. Schmaier $\mathrm{AH}$. The kallikrein-kinin and the renin-angiotensin systems have a multilayered interaction. Am J Physiol Regul Integr Comp Physiol. 2003;285:R1-13.

50. Colman RW, Bradford HN, Warner AH. High molecular weight kininogen, the extracellular inhibitor of thiol proteases, is deficient in hamsters with muscular dystrophy. Thromb Res. 1989;54:115-23.

51. Amin H, Mohsin S, Aslam M, Hussain S, Saeed T, Ullah MI, Sami W. Coagulation factors and antithrombin levels in young and elderly subjects in Pakistani population. Blood Coagul Fibrinolysis. 2012;23:745-50.

52. Kourteva Y, Schapira M, Patston PA. The effect of sex and age on antithrombin biosynthesis in the rat. Thromb Res. 1995; 78:521-9.

53. Kostka B, Para J, Drygas W, Kostka T. Antithrombin III activity in the elderly-association with cardiovascular disease risk factors. Przegl Lek. 2005;62:35-8.

54. Corbella E, Miragliotta G, Masperi R, Villa S, Bini A, de Gaetano G, Chiumello G. Platelet aggregation and antithrombin III levels in diabetic children. Haemostasis. 1979;8:30-7.

55. Duru S, Koca U, Oztekin S, Olguner C, Kar A, Coker C, Ulukus C, Taşcł C, Elar Z. Antithrombin III pretreatment reduces neutrophil recruitment into the lung and skeletal muscle tissues in the rat model of bilateral lower limb ischemia and reperfusion: a pilot study. Acta Anaesthesiol Scand. 2005;49:1142-8.

56. Cadroy Y, Pierrejean D, Fontan B, Sie P, Boneu B. Influence of aging on the activity of the hemostatic system: prothrombin fragment $1+2$, thrombin-antithrombin III complexes and D-dimers in 80 healthy subjects with age ranging from 20 to 94 years. Nouv Rev Fr Hematol. 1992;34:43-6.

57. Van der Bom JG, Bots ML, van Vliet HH, Pols HA, Hofman A, Grobbee DE. Antithrombin and atherosclerosis in the Rotterdam Study. Arterioscler Thromb Vasc Biol. 1996;16:864-7.

58. Sun YF, Cao J, Li XL, Fan L, Wang Q, Wang H, Zhang H, Yang L, Zhang F. Correlation of coronary heart disease with multiple genes, gene polymorphisms and multiple risk factors in old Chinese Han patients. Zhongguo Ying Yong Sheng Li Xue Za Zhi. 2012;28:411-7.

59. Murata S, Kobayashi A, Takeuchi T, Nakajima H, Yoshida A, Kurosawa Y, Miki S, Mizoguchi T, Sakurai T, Kawatani A. Clinical evaluation of the efficacy of an antithrombin agent "Argatroban" combined with exercise therapy on increase of the skeletal muscle blood flow. Nihon Geka Hokan. 1996;65:109-19. 